\title{
Quando falta o corpo caloso
}

\section{When the corpus callosum is missing}

A agenesia do corpo caloso (AgCC) é uma malformação cerebral comum, com incidência estimada de 1:4000 e que pode ser resultante de fatores genéticos ou ambientais. Pode apresentar-se isoladamente ou associada a outras condições como: anomalias estruturais cerebrais (hidrocefalia ou outras), disfunção neurológica (epilepsia, macro ou microcefalia alterações visuais ou auditivas), malformações extracerebrais, anomalias cromossómicas ou doenças metabólicas. 0 seu diagnóstico faz-se por métodos de neuroimagiologia, cuja disseminação conduziu ao diagnóstico mais precoce e/ou em indivíduos com alterações mais subtis. São vários os casos descritos na literatura de achados acidentais de AgCC, o que sugere que muitos casos são assintomáticos ou com alterações tão discretas que não despertam a atenção clínica.

Apresenta-se o caso de um homem de 49 anos, camionista, com antecedentes de Diabetes Mellitus tipo 2 medicado com antidiabéticos orais e cefaleias frequentes medicado com pregabalina. Recorreu ao serviço de urgência por vários episódios de parestesias na face e hemicorpo direito nas últimas 24 horas. Ao exame neurológico apresentava ligeira hipostesia à direita, sem outras alterações. Destaca-se neste caso o achado ocasional de AgCC que se verificou tratar de um achado ocasional, que não justificavas as queixas do doente.

\section{Bibliografía}

1. Palmer EE, Mowat D. Agenesis of the corpus callosum: a clinical approach to diagnosis. Am J Med Genet C Semin Med Genet. 2014;166C(2):18497.

2. Siffredi V, Anderson V, Leventer RJ, SpencerSmith MM. Neuropsychological Profile of Agenesis of the Corpus Callosum: A Systematic Review. Developmental Neuropsychology. 2013: 38:1, 36-57.

\section{Diagnóstico:}

\section{Agenesia do corpo caloso}

\section{Marta Oliveira Ferreira, Alice Pinheiro \\ Centro Hospitalar do Médio Ave - Unidade de Famalicão}

Correspondencia: martaoliveiraferreira@gmail.com

Como citar este artículo: Oliveira Ferreira $M$, Pinheiro A

Quando falta o corpo caloso. Galicia Clin 2017: 78 (1): XX-XX

Recibido: 26/06/2016; Aceptado: 07/09/2016
Figure 1. Agenesia do corpo caloso e ausência de lesões vasculares agudas

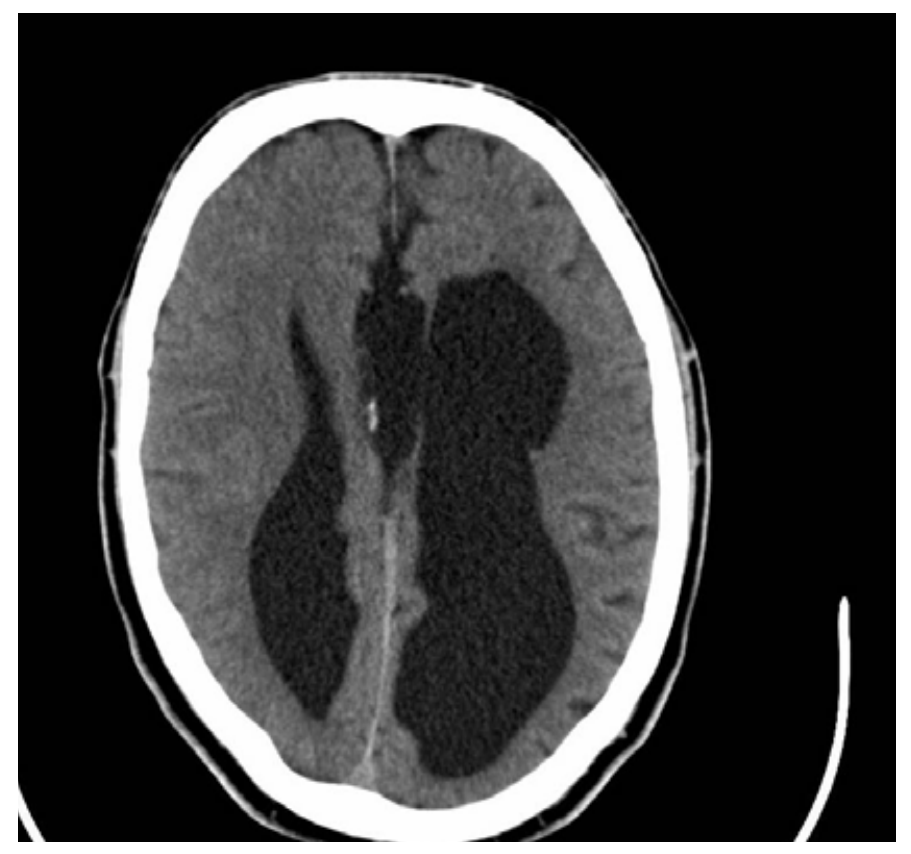

